\title{
The causative agent of downy mildew Peronospora brassicae Gaeum. f. brassicae (Gaeum.) on winter false flax (Camelina sativa (L.) Crantz.): the search for a source of disease resistance in the conditions of the Krasnodar region
}

\author{
Oksana Serdyuk ${ }^{*}$,Victoria Trubina, and Lyudmila Gorlova \\ V.S. Pustovoit All-Russian Research Institute of Oil Crops, Krasnodar, 350038, Russia
}

\begin{abstract}
In recent years, in the conditions of the central zone of the Krasnodar region, downy mildew has become the most dangerous disease of winter false flax that affects the crop yield. Either the infected plants do not develop reproductive organs or these organs are undeveloped. The development of varieties resistant to infection by the disease causative agent allows efficient reducing the seed yield loss of winter false flax due to downy mildew without the use of chemical products. In 2015-2019, we conducted an assessment of the breeding material (528 cultivar samples) of winter false flax for resistance to downy mildew affection on a natural infection background. We determined that the causative agent of the disease is Peronospora brassicae Gaeum. $f$. brassicae (Gaeum.) Dzhan. We divided all cultivar samples into groups according to their resistance to the disease: immune, resistant, weakly resistant, weakly susceptible, susceptible. As a result of research, we selected 5 breeding samples (\#\# $724,726,728,730,738$ ) that were immune to downy mildew in the course of several years, with yield exceeding the standard variety Karat by 0.22 $0.38 \mathrm{t} / \mathrm{ha}$, and with oil content exceeding the standard by $0.2-0.5 \%$. We proposed to use the selected cultivar samples in the breeding process with the aim of developing new false flax varieties resistant to downy mildew.
\end{abstract}

\section{Introduction}

Currently, false flax (Camelina sativa (L.) Crantz.) is a promising oil crop of the cruciferous family due to its early ripening and undemanding nature to weather conditions, which allows it to be grown in different soil and climatic conditions. The oil of false flax

\footnotetext{
*Corresponding author: oserduk@mail.ru
} 
seeds is more oxistable and environmentally safe in comparison with other vegetable oils. It is increasingly used for food purposes, the production of pharmaceuticals, as well as a biofuel and high-value chemical raw materials [1-4].

The cake remaining after expression of oil from the false flax seeds is a valuable highprotein, easily digestible feed for farm animals. The protein content in it is $23.2-29.1 \%$ [5].

Under cultivation, the diseases of various etiologies affect winter false flax during the growth season: downy mildew (the causative agent is Peronospora brassicae f. brassicae Gäeum), powdery mildew (the causative agent is Erysiphe communis $f$. brassicae Hammarl), Fusarium blight (the causative agent is the fungi of Fusarium Link genus), white rot (the causative agent is Sclerotinia sclerotiorum (Lib.) de Bary), Alternaria blight (the causative agent is the fungi of Alternaria Nees genus) [6-9].

The chemical method of plant protection is used most often to reduce the harmfulness of the pathogens that cause the false flax diseases. However, in addition to chemical control of the prevalence and development of diseases, research are being conducted in different countries to identify the sources of resistance of false flax to the diseases, most harmful in the specific climatic conditions [10-14].

In recent years, in the conditions of the central zone of the Krasnodar region, downy mildew has become the most dangerous disease of winter false flax that affects the crop yield. The plants affected by the disease are far behind in growth, standing out prominently against the background of healthy plants. The leaves of such plants are pale green, covered with a loose white coating - the sporulation of the pathogen. Either the infected plants do not develop reproductive organs or these organs are undeveloped. In case of severe disease affection, the plants of winter false flax dry out and die quickly.

The development of varieties resistant to infection by the disease causative agent allows efficient reducing the seed yield loss of winter false flax due to downy mildew without the use of chemical products. To do this, it is necessary to search for sources of resistance to downy mildew, regularly evaluating breeding material and collection samples of winter false flax, and introduce them into crossings through conduction of gradual work.

The aim of this work was to identify the sources of false flax resistance to downy mildew in the conditions of the central zone of the Krasnodar region.

\section{Materials and methods}

We conducted research in 2015-2019 in V.S. Pustovoit All-Russian Research Institute of Oil Crops (VNIIMK), Krasnodar on the breeding material of winter false flax in the field conditions on a natural infection background. In 2015, we examined 128 cultivar samples of false flax, in 2016-2017 - 200. In 2018, we made a separate nursery for the progeny assessment from the false flax samples with various degree of downy mildew resistance. We studied 24 samples there. We sowed each sample on a plot of $7.5 \mathrm{~m}^{2}$ in three replications. We chose the sample \# 720 as a control for downy mildew susceptibility as it was the most severely affected by the disease in previous years. We used variety Karat of VNIIMK breeding as a standard of economic character.

We determined the prevalence of downy mildew in breeding samples of winter false flax according to the generally accepted formula:

$$
\mathrm{P}=\frac{\mathrm{n}}{\mathrm{N}} 100 \%
$$

where $\mathrm{P}-$ is the disease prevalence, $\%$;

$\mathrm{n}-$ is the number of infected plants in a sample, pcs.;

$\mathrm{N}-$ is the total number of accounted plants in a sample, pcs. 
We divided the disease prevalence into low, medium and high: low - from 0.1 to $20.0 \%$ of plants in the sample were affected; medium - from 20.1 to $60.0 \%$ of plants in the sample were affected; high $-60.1 \%$ of plants in the sample or more were affected.

Based on the data of downy mildew prevalence, we divided all studied breeding samples of false flax into groups according to the disease resistance using the UPOV scale that we modified [15]:

0 points - all plants in a sample are without symptoms of the disease (immune);

1 point - from 0.1 to $20.0 \%$ of plants in a sample have symptoms of the disease (resistant);

2 points - from 20.1 to $40.0 \%$ of plants in a sample have symptoms of the disease (weakly resistant);

3 points - from 40.1 to $60.0 \%$ of plants in a sample have symptoms of the disease (weakly susceptible);

4 points -60.1 of plants in a sample of more sample have symptoms of the disease (susceptible).

Every year, in April, we evaluated the affection of winter false flax breeding samples by downy mildew, when there is a wide manifestation of signs of plants infection with disease in the conditions of the central zone of the Krasnodar region.

We identified the causative agent of downy mildew in the laboratory conditions using a Motic BA300 microscope with 40 magnification. We determined the oil content of winter false flax seeds on a Matrix-1 IR spectrometer.

During all years of research (2015-2019), the weather conditions in March-April were favorable for the development of the downy mildew pathogen: the average air temperature in March was 6.3-9.0 ${ }^{\circ} \mathrm{C}$, in April - 11.1-13.8 $\mathrm{C}$; the precipitation in March was 29.2-94.0 mm and 25.6-67.5 mm in April; the relative humidity in March was high - 64-77\%, and slightly lower in April, 55-71\%, but sufficient for the pathogen development.

\section{Research results}

We identified the first plants of winter false flax with downy mildew symptoms in 2015. The most part of affected false flax plants do not grow higher than $20 \mathrm{~cm}$. The leaves of such plants differ from the leaves of healthy plants in a light green color; a white coating is noted on their underside - the sporulation of the pathogen. Flowers and, consequently, pods are not developed on the infected plants, which negatively affects the yield of false flax. When plants are severely affected by the disease, they dry out quickly and become completely white coated (Fig. 1).

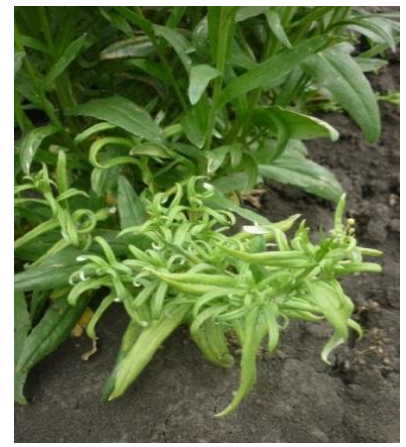

a

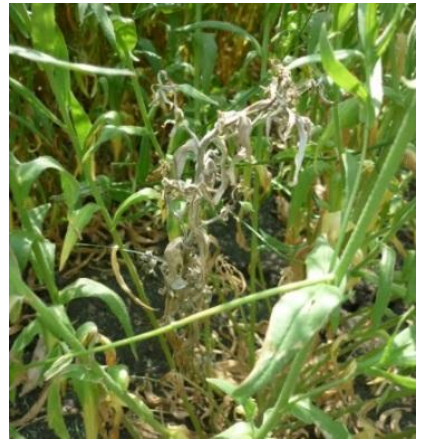

b

Fig. 1. The affection of false flax by downy mildew (the causative agent is Peronospora brassicae $f$. brassicae Gäeum.) (orig.): a) an affected plant with light yellow leaves against a background of healthy plant; b) completely dried affected plant 
The identification of pathogen isolates in laboratory conditions showed that the causative agent of downy mildew of winter false flax in the central zone of the Krasnodar region is Peronospora brassicae f. brassicae Gäeum. (Fig. 2).

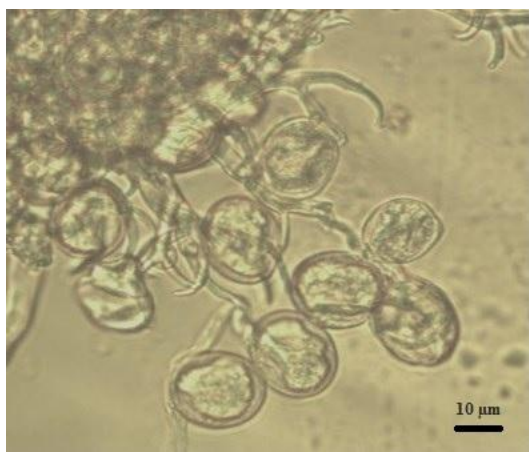

a

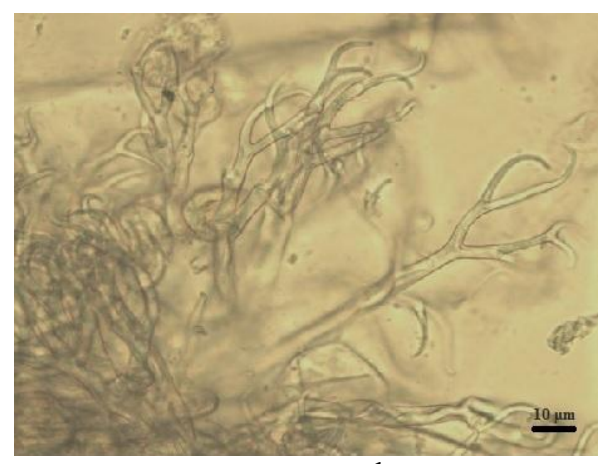

b

Fig. 2. Peronospora brassicae f. brassicae Gäeum. (orig.): a) spores; b) conidiophores

In 2015, the number of false flax samples, in which there were plants affected by the diseases, amounted to $7.0 \%$ of the total examined breeding material. The prevalence of downy mildew is these samples was low $-0.5-2.0 \%$ (Table 1 ).

Table 1. The downy mildew disease assessment of breeding samples of winter false flax, V.S. Pustovoit All-Russian Research Institute of Oil Crops, 2015-2017

\begin{tabular}{|c|c|c|c|c|}
\hline \multirow{2}{*}{ Research year } & \multirow{2}{*}{$\begin{array}{c}\text { The total } \\
\text { number of } \\
\text { samples, pcs. }\end{array}$} & \multicolumn{2}{|c|}{$\begin{array}{c}\text { The number of affected } \\
\text { samples }\end{array}$} & \multirow{2}{*}{$\begin{array}{c}\text { The disease prevalence } \\
\text { on samples, \% }\end{array}$} \\
\cline { 3 - 4 } & 128 & 9 & $\begin{array}{c}\% \text { from the } \\
\text { total number }\end{array}$ & \\
\hline 2015 & 200 & 195 & 97.5 & $0.5-2.0$ \\
\hline 2016 & 200 & 197 & 98.5 & $0.4-60.0$ \\
\hline 2017 & & & & $0.6-87.3$ \\
\hline
\end{tabular}

In 2016, the number of samples of winter false flax with the presence of plants affected by the disease increased sharply, amounting to $97.5 \%$ of the total number of examined samples. The prevalence of downy mildew on them ranged from low $(0.4 \%)$ to medium $(60.0 \%)$.

In 2017, the number of false flax samples with affected plants increased by $1.0 \%$, compared with the previous year, and amounted to $98.5 \%$ of the total number of samples. The prevalence of the disease on them ranged from low $(0.6 \%)$ to high $(87.3 \%)$.

In 2016-2017, the number of false flax samples without signs of downy mildew manifestation amounted to 2.5 and 1.5 , respectively.

In 2018, we selected the breeding samples of winter false flax for further study in a nursery for the progeny assessment. We chose the samples which in previous years proved to be susceptible (the disease prevalence on them was 60.1-87.3\%), resistant (the disease prevalence on them was $0.3-0.6 \%$ ) and immune (there were no signs of the disease manifestation on all plants) to downy mildew.

The assessment of affection of false flax samples by the disease in the nursery showed that on susceptible samples of previous years the disease prevalence varied from low to medium, amounting to $5.8-41.0 \%$, and it was low on resistant samples, amounting to 3.6$4.4 \%$. The immune samples of false flax reacted differently to infection with a pathogen: in 2018 , the disease prevalence on them was $0-1.7 \%$. From the total number of immune 
samples, we selected five samples in which no plants with signs of downy mildew affection were observed for 3 years (Table 2).

Table 2. The downy mildew prevalence on the samples of winter false flax of different groups of disease resistance, V.S. Pustovoit All-Russian Research Institute of Oil Crops, 2018

\begin{tabular}{|l|c|c|}
\hline \multicolumn{1}{|c|}{ The resistance group of samples } & $\begin{array}{c}\text { The number of } \\
\text { samples, pcs. }\end{array}$ & $\begin{array}{c}\text { The disease prevalence } \\
\text { on samples, } \%\end{array}$ \\
\hline Susceptible & 8 & $5.8-41.0$ \\
\hline Resistant & 8 & $3.6-4.4$ \\
\hline \multirow{2}{*}{ Immune } & 5 & 0 \\
\hline \#720 (susceptible sample, control) & 3 & $0.8-1.7$ \\
\cline { 2 - 3 } & 1 & 41.5 \\
\hline
\end{tabular}

In 2018, the highest disease prevalence was noted on the control sample of false flax \#720 (susceptible sample) - $41.5 \%$.

In 2019, we continued the study of false flax samples immune to downy mildew in the nursery for the progeny assessment. This year, there were no signs of downy mildew manifestation on five samples that were immune in previous years; the disease prevalence on the remaining three studied samples of false flax was 20.0-26.0 \%.

The analysis of the productive qualities of false flax seeds showed that in 2018 the yield of the studied samples exceeded the standard variety Karat: it was significantly for samples \#\# 724, 728, 730, 738 (by 0.23-0.34 t/ha) and insignificantly for sample \# 726 (by 0.22 $\mathrm{t} / \mathrm{ha}$ ). In 2019, the seed yield indicators of all samples were significantly higher than the standard variety (by $0.22-0.38 \mathrm{t} / \mathrm{ha}$ ) (Table 3 ).

Table 3. The productivity of selected breeding samples of winter false flax, V.S. Pustovoit AllRussian Research Institute of Oil Crops, 2018-2019

\begin{tabular}{|l|c|c|c|c|}
\hline \multirow{2}{*}{ Sample } & \multicolumn{2}{|c|}{ Seed yield, $\mathrm{t} / \mathrm{ha}$} & \multicolumn{2}{c|}{ Oil content of seeds, $\%$} \\
\cline { 2 - 5 } & 2018 & 2019 & 2018 & 2019 \\
\hline 724 & 2.10 & 2.06 & 40.00 & 39.80 \\
\hline 726 & 1.98 & 1.90 & 40.00 & 39.60 \\
\hline 728 & 1.99 & 1.93 & 40.20 & 39.80 \\
\hline 730 & 2.08 & 1.96 & 40.00 & 39.80 \\
\hline 738 & 2.10 & 2.02 & 40.30 & 39.70 \\
\hline $\begin{array}{l}\text { Karat } \\
\text { (standard) }\end{array}$ & 1.76 & 1.68 & 39.80 & 39.40 \\
\hline HCP $_{05}$ & 0.22 & 0.20 & 0.19 & 0.17 \\
\hline
\end{tabular}

In 2018, the oil content of false flax seeds in samples \#\# 728, 738 exceeded significantly the standard variety Karat $(0.4-0.5 \%)$, in samples \#\# 724, 726, 730 insignificantly (by $0.2 \mathrm{t} / \mathrm{ha}$ ). In 2019 , the oil content of seeds was significantly higher than the standard variety for all the studied samples of false flax (by 0.3-0.4\%) with the exception of \# 726, the oil content of seeds of which was $0.2 \%$ higher than the standard.

Based on the received results, we proposed the selected samples of winter false flax for use in the breeding process with the aim of developing new high-yielding, downy mildewresistant cultivars with high oil content. 


\section{Conclusions}

We established that downy mildew of winter false flax in the conditions of the central zone of the Krasnodar region is caused by Peronospora brassicae f. brassicae Gäeum. As a result of the research, we selected breeding samples of false flax \#\# 724, 726, 728, 730, 738 , immune to the disease for several years.

Among the immune samples, there were samples of winter false flax (\#\# 724, 728, 730, 738 ), the productivity of which significantly exceeded the standard variety Karat - by 0.23 $0.34 \mathrm{t} / \mathrm{ha}$ in 2018 and by $0.22-0.38 \mathrm{t} / \mathrm{ha}$ in 2019 . The oil content of false flax seeds significantly exceeded the standard in samples \#\# 728 and 738 in both years of study: by $0.4-05 \%$ in 2018 and by $0.3-0.4 \%$ in 2019 .

We proposed the selected samples (\#\# 724, 726, 728, 730, 738) for use in the breeding process with the aim of developing new downy mildew-resistant cultivars of winter false flax, considering that the samples \#\# 728, 738 are also the sources of high productivity and high oil content of seeds of this crop.

\section{References}

1. M. C. Campbell, A. F. Rossi and W. Erskine, Crop and Pasture Science 64(4), 388398 (2013) https://doi.org/10.1071/CP13054.

2. Surinder Kumar Gupta, Breeding Oilseed Crops for Sustainable Production. Opportunities and Constraints. Chapter 3 - Brassicas, 33-53 (2016) https://doi.org/10.1016/B978-0-12-801309-0.00003-3.

3. Shivani Chaturvedi, Amrik Bhattacharya, Sunil Kumar Khare, Geetanjali Kaushik, Handbook of Environmental Materials Management. Camelina sativa: An Emerging Biofuel Crop, 1-38 (2017) https://link.springer.com/referenceworkentry/10.1007\%2F978-3319-58538-3 110-1.

4. Vanessa D. de Mello, Ingrid Dahlman, Maria Lankinen, Sudhir Kurl, Leena Pitkänen, David E. Laaksonen, Ursula S. Schwab \& Arja T. Erkkilä, Nutrition \& Diabetes, 9, 1 (2019) https://doi.org/10.1038/s41387-018-0069-2.

5. R. M. Harveson, D. K. Santra, M. L. Putnam, M. Curtis, and A. D. Pavlista, Plant Health Progress. Online (2011) https://doi.org/10.1094/PHP-2011-1014-01-BR.

6. Yuan Lixia, Li Runzhi, Front. Plant Sci., 2, https://doi.org/10.3389/fpls.2020.00011.

7. E. M. Babiker and S. H. Hulbert, Plant Dis. 96, 1670-1674, (2012) https://doi.org/10.1094/PDIS-02-12-0212-RE.

8. Dariusz Załuski, Józef Tworkowski, Michał Krzy zaniak, Mariusz J. Stolarski, Jacek Kwiatkowski, Agronomy, 10(1), 64 (2020) https://doi.org/10.3390/agronomy10010064.

9. Mary E. Burrows, Robert Harveson, High Plains Integrated Pest Management. https://wiki.bugwood.org/HPIPM:Downy Mildew_Camelina).

10. Federica Zanetti, ChristinaEynck, Myrsini Christou, Michal Krzyżaniak, Daria Righini, Efthimia Alexopoulo, Mariusz J. Stolarski, Eibertus N. Van Loo, Debbie Puttick, Andrea Monti, Industrial Crops and Products, 107, 602-608 (2017) https://doi.org/10.1016/j.indcrop.2017.06.022.

11. Maria I. Purnamasari, William Erskine, Janine S. Croser, Ming Pei You, Martin J. Barbetti, Plant Disease 103(11), 2884-2892 (2019) https://doi.org/10.1094/PDIS-03-190664-RE.

12. C. Eynck, G. Séguin-Swartz, W.E. Clarke, I.A. Parkin, Mol. Plant. Pathol. 13(8), 887-899 (2012) DOI: 10.1111/j.1364-3703.2012.00798.x. 
13. Sandhya Rawat, Sajad Ali, N.M. Chamil, Ind. Phyt., (2015) https://scinapse.io/papers/2478516979.

14. Maria Purnamasari, Greg Cawthray, Martin Barbetti, William Erskine, Janine Croser Plant. Disease, 99(11), 1544-1549 (2015) https://doi.org/10.1094/PDIS-12-14-1297-RE.

15. Brown Mustard, UPOV Code: BRASS_JUN Brassica juncea (L.) Czern. Guidelines for the conduct of tests for distinctness, uniformity and stability (2015) https://www.upov.int/edocs/mdocs/upov/en/twv 49/tg_brass_jun_proj_3.pdf. 